\title{
Educação popular no contexto da globalização neoliberal
}

\author{
Popular Education in the context of neoliberal globalization
}

\author{
José Wnilson Figueiredo \\ Liria Ângela Andrioli \\ Walter Frantz \\ Universidade Regional do Noroeste do Estado do Rio Grande do Sul
}

\section{Resumo}

$\bigcirc$ presente artigo visa apresentar uma reflexão acerca da educação popular como uma prática possível à conjuntura social contemporânea. Trata-se de um uma conjuntura marcada pela racionalidade téc-

86 nico-instrumental da globalização neoliberal, ancorada no individualismo, na homogeneização cultural e na monetarização da vida. Apoia-se em conceitos de educação popular, como uma alternativa possível, no que concerne à ética e à política, em favor de uma vida em que se insiram todos os seres humanos. Para tanto, tem-se, como ponto de partida, o diálogo intercultural em torno da ética e da esperança, em prol de possíveis caminhos, que possibilitem a emergência de uma civilização centrada na cooperação, ancorada no respeito às diferenças, na compaixão e na responsabilidade com o/a outro/a em oposição à lógica de mercado da educação da globalização neoliberal.

Palavras-chave: Educação popular. Globalização neoliberal. Utopia.

\begin{abstract}
The present article aims to bring up a reflection about the popular education as a possible alternative to the social contemporary conjuncture. It is a coincidence marked by the technical and instrumental rationality of the neoliberal globalization, rooted in the individualism, in the cultural of homogenization and in the monetization of life. We were based on the concepts of popular education, as a possible alternative, regarding to ethics and to politics in favor of a life where all the human beings could be inserted. Therefore, we take as a base the intercultural dialogue around ethics and hope, in favor of possible paths, that enable the emergence of a civilization based on cooperation, anchored to respect for differences, to compassion and responsibility with others as opposed to the logic of the education market of the neoliberal globalization.
\end{abstract}

Keywords: Popular education. Neoliberal globalization. Utopia. 
A globalização neoliberal traz, em seu 'projeto de sociedade', uma lógica, atrelada à racionalidade do capital, tendo como motor o processo de acumulação pela extração da mais-valia, em âmbito global. Na visão de Santos (2001, p. 23), sob essas condições, estabelece-se um processo de globalização perversa cujo ápice é a "[...] internacionalização do mundo capitalista." O mesmo autor (SANTOS, 2001, p. 19-20) denuncia que "[...] a globalização está se impondo como uma fábrica de perversidades [...]", seja pelo desemprego e pela pobreza crescentes ou pelo aprofundamento de "[...] males espirituais e morais, como os egoísmos, os cinismos, a corrupção." Hoje, certamente, na esteira da crise econômico-financeira, essa perversidade não se manifesta apenas em países periféricos, na África ou na América Latina, mas também na Europa, onde o índice de desemprego é cada vez maior e as conquistas sociais estão sendo desmontadas. Trata-se de um processo cuja lógica se hegemoniza e submete as relações sociais a uma percepção unidimensional da vida: produzir e consumir.

Sob a força da racionalidade do sistema capitalista, os referenciais coletivos cedem lugar à individualidade, cada vez mais, controlada pela racionalidade do capital, fragmentando-se em individualismos. Facilmente, diante de tal processo, projetos pessoais se desvinculam de um referencial coletivo ou público, dissolvendo a identificação social maior. "O individualismo aparece mediante projetos pessoais egoístas que, além de marginalizarem e desprezarem a dimensão social coletiva, fazem uso de aspectos que eticamente seriam coletivos, para fins pessoais." (SOETHE, 1996, p. 22). Têm-se como resultados a exclusão social e um pensamento único e hegemônico, que carrega consigo regras e valores orientadores das ações e das interações humanas, submetidos à economia. Desse processo, decorre uma racionalidade de gestão que "[...] produz sistemas de direção que se alicerçam no aprisionamento da vontade e na expropriação das possibilidades de governar da maioria [...]." (CAMPOS, 2000, p. 23).

Segundo Guattari e Rolnik (2000), afirma-se uma cultura capitalística pela qual se transmitem sistemas de modelização e por meio dos quais se exerce poder no processo de produção de uma subjetividade social que unifica, isto é, que modela todos os indivíduos, independentemente dos lugares que ocupem na economia, na política, etc. A modelização "[...] diz respeito aos comportamentos, à sensibilidade, à percepção, à memória, às relações sociais [...]." (GUATTARI; ROLNIK, 2000, p. 28). De acordo com os autores, 
no sistema capitalístico, a produção da subjetividade se dá em escala internacional. "Trata-se de sistemas de conexão direta entre as grandes máquinas produtivas, as grandes máquinas de controle social e as instâncias psíquicas que definem a maneira de perceber o mundo." (GUATTARI; ROLNIK, 2000, p. 27). Desse modo, se instaura uma ordem cultural, uma ordem social, uma estrutura de poder.

A ordem capitalística é projetada na realidade do mundo e na realidade psíquica. Ela incide nos esquemas de conduta, de ação, de gestos, de pensamento, de sentido, de sentimento, de afeto, etc. Ela incide nas montagens da percepção, da memorização, ela incide na modelização das instâncias intra-subjetivas [...]. (GUATTARI, ROLNIK, 2000, p. 42).

Segundo Marcuse (1973, p. 28), quanto mais racional, produtiva, técnica e total se torna o controle da sociedade, tanto mais inimagináveis se tornam os modos e os meios pelos quais os indivíduos controlados poderão romper sua submissão ao poder dessa racionalidade, pois a superação dessa situação depende da sua compreensão crítica, sendo que "[...] o surgimento 88 dessa consciência é sempre impedido pela predominância de necessidades e satisfações que se tornaram, em grande parte, do próprio indivíduo."

Hoje, cultura e poder se fundem na dinâmica da economia de mercado. Parece ocorrer, cada vez mais, uma conformação ativa à lógica do mercado capitalista que ganha expressão no consumo, restringindo a liberdade de escolha dos indivíduos. Dessa lógica, nasce uma ampla estrutura de controle social - com o sentido da conformação - que não se reduz ao poder de apropriação da mais-valia econômica, mas na apropriação do próprio modo de ser das pessoas, ainda que, pobres ou sem capital, as pessoas sejam, culturalmente, incorporadas ao sistema capitalista. Cada vez mais, a lógica capitalista ordena e conforma os diferentes indivíduos, no campo da economia, da política, da cultura, da educação, uniformizando-os em modo de pensar e agir.

Romper com essa lógica é uma tarefa árdua, mas não parece impossível diante da concepção de que "[...] o que existe na vida humana e social está em perpétua transformação, tudo é perecível, tudo está sujeito ao fluxo da história." (LÖWY, 1989, p. 14). Assim, tem-se como pressuposto que o desafio está na problematização. Problematizar, refletir, questionar acerca da 
sociedade, parece um início de efetivas mudanças estruturais. Esse pressuposto abre espaço à educação, especialmente, à educação popular como forma de resistência e luta. (MEJÍA, 2012 ).

Mas afinal, o que se entende por educação popular? De acordo com Torres (2007), não existe uma única compreensão ou definição de educação popular. $\bigcirc$ autor aponta algumas características que podem formar uma compreensão de núcleo comum: leitura crítica da ordem social vigente, intencionalidade política emancipadora, contribuição ao fortalecimento dos setores dominados como sujeitos históricos capazes de promover a transformação social, a construção e o emprego de metodologias educativas dialógicas, participativas e ativas. Enfim, a educação popular tem suas raízes na luta pela promoção das necessidades e interesses das camadas populares, isto é, das camadas sociais menos favorecidas. Pode-se reconhecer, portanto, o lugar e a importância da educação popular no processo de problematização e de reflexão acerca de contextos sociais específicos ou da própria sociedade, assim, constituindo-se em instrumento de luta social. A educação popular, de modo peculiar, pode vir a ser um importante instrumento na medida em que se propõe a ser uma prática social e cultural, que contraria a ordem social vigente de opressão e submissão.

Os educadores populares assumem esta como uma concepção educativa que tem suas práticas, conceitualizações, pedagogias e metodologias, mediante as quais fazem vigente sua proposta de indignação ética frente ao capitalismo atual e fazem uma proposta de emancipação e de transformação desta sociedade para construir uma mais humana e justa a partir dos processos educativos, mediante os quais realizam seu trabalho na sociedade. (MEJIA, 2012 , p. 64).

Bauman (201 1 , p. 7) escreve: "O esforço para compreender o mundo [...] é de fato uma luta. Uma luta, pode-se dizer, árdua [...] para sempre inacabada. A vitória final nessa guerra continua obstinadamente para além do horizonte." Aponta, porém, para três armas de luta que todos os seres humanos possuem e que podem conduzir para além do horizonte: esperança, coragem e obstinação. Aqui cabe perguntar sobre a possibilidade de a educação popular abrigar essas armas de luta em prol de mudanças. 
Nessa perspectiva, o presente texto pretende trazer para a reflexão a educação popular como esperança e como um processo indispensável à assunção de uma pedagogia e uma racionalidade centrada no diálogo intercultural, ou seja, na promoção de "uma educação para o reconhecimento do 'outro', para o diálogo entre os diferentes grupos sociais e culturais." (CANDAU, 2008 , p. 8). Torna-se essencial, neste contexto, levar em consideração os processos político-pedagógicos, voltados para a intercooperação, entre os sujeitos envolvidos, com vistas à efetivação de práticas sociais que tenham sintonia entre os saberes populares e os saberes científicos. De igual forma, essa racionalidade deve estar sustentada em fundamentos epistemológicos e políticos com base na solidariedade, na alteridade, na responsabilidade, no amor e na reciprocidade entre as pessoas, com vistas à emergência de um mundo voltado à construção de conhecimentos capazes de gerar uma globalização cooperativa, fundada na ética, em contraponto à globalização capitalista.

Esses conhecimentos deverão ser elaborados com base no diálogo entre a teoria e a prática das diversas experiências culturais, existentes nas várias regiões do mundo, na perspectiva da busca da igualdade de direitos e do reconhecimento das diferenças, no âmbito da cultura, da etnia, da língua, 90 da religião, das relações de gênero e das classes sociais.

A educação popular, portanto, prescinde do diálogo intercultural como elemento de complementaridade e de aglutinação entre as diversas culturas do mundo e entre os diversos saberes produzidos pelas mesmas, no que se refere ao sonho e à esperança em torno da emergência de uma civilização cooperativa. Para que isso ocorra, é necessário que se estabeleçam profundas reflexões acerca das contradições sociais presentes no mundo da globalização neoliberal, as quais se manifestam na desigualdade social acentuada dos países do sul, concomitantemente com a riqueza dos países do norte.

Vale salientar, portanto, que o debate sobre as contradições sociais pode levar à consciência política e à constituição de forças capazes de se contrapor ao sistema. Pelo reconhecimento, pela análise e pela interpretação das contradições, isto é, pela conscientização, os indivíduos podem reconstruir caminhos pedagógicos da cooperação ao se fazerem sujeitos e atores políticos pelo debate sobre a experiência social das contradições, instituindo um processo de interação educativa. 
projeto educativo revolucionário proposto por Paulo Freire se inscreve em reação contra a educação bancária que não considera suficientemente o papel participativo do homem ou da mulher na construção do mundo. $\bigcirc$ homem sujeito de sua história, dialogando com seus parceiros humanos, é capaz de atingir um nível de consciência crítica que the permita de transformar a sociedade circundante. (MORIN, 2004, p. 76).

Para Freire (2005), o ser humano se relaciona com o mundo como sujeito de conhecimento e isso o leva ao conceito de conscientização como tomada de consciência crítica e de ação transformadora da realidade que o oprime. A conscientização se dá na relação dialógica com o outro, em processos sociais de interação que levam à constituição de sujeitos de sua história. Freitas (2008, p. 99-100) afirma que: "É através da conscientização que os sujeitos assumem seu compromisso histórico no processo de fazer e refazer o mundo, dentro de possibilidades concretas, fazendo e refazendo também a si mesmos."

Segundo Torres (2007), todas as propostas de educação popular, na América Latina, fazem referência ao caráter injusto da ordem social de tipo capitalista. De acordo com o autor, a educação popular pode ser definida como práticas sociais e elaborações discursivas nos espaços da educação com a intenção de contribuir para que as camadas populares possam se constituir sujeitos de transformação da ordem social injusta.

\section{A lógica do capital da globalização neoliberal}

Em meio à globalização neoliberal, a humanidade atravessa uma crise sem precedentes do ponto de vista da quase ausência da ética em favor da vida e da falta de responsabilidade perante o futuro do planeta, principalmente, no que se refere à manutenção das condições mínimas e indispensáveis para a sobrevivência de todos os seres vivos. Essa lógica está fundada no estabelecimento do dinheiro como medida de todos os aspectos da existência humana e no conhecimento científico fundado na racionalidade cognitivo-instrumental, que se caracteriza, segundo Santos, (2009), pela aplicação técnica da ciência voltada para os aspectos utilitários do interesse, do individualismo e do lucro. 
Essa aplicação técnica da ciência trouxe e traz consequências desastrosas para os seres humanos, do ponto de vista social e político, já que a leitura, a interpretação e a solução dos problemas da realidade sócio-histórica, em que estão inseridos os homens e as mulheres, foram e são abordados apenas pela ótica da ciência como aplicação técnica a serviço da lógica de acumulação do capital. Desconsideram-se, assim, as implicações éticas dessa aplicação com relação ao cuidado com a natureza e com a preservação de uma vida digna a todos os seres humanos, no que concerne ao acesso à educação, à saúde, à liberdade e a uma renda suficiente para a sobrevivência. A aplicação técnica da ciência, sustentada pelo ideário pedagógico da racionalidade cognitivo-instrumental, passa, nesse viés, a reforçar a desigualdade social na medida em que se associa ao poder da globalização neoliberal excludente, principalmente, pela imposição aos grupos sociais da leitura da realidade, a partir dos corolários dessa lógica hegemônica. Esta, por sua vez, se estrutura em torno dos seguintes pressupostos: da validade apenas do conhecimento científico como categoria adequada para a explicação da realidade, da monetarização da vida, do consumo, do individualismo e da supremacia da técnica sobre a ética na compreensão e na interpretação de

92 como se estruturam as relações sociais nos espaços da sociedade.

Essa supremacia da técnica sobre a ética provoca a invisibilidade das culturas e dos saberes locais, inerentes à pedagogia dos povos subalternos, gerando certa "homogeneização cultural" na construção do conhecimento. Isso se deve à adoção do saber científico em detrimento dos outros saberes, ligados à experiência cotidiana das pessoas, que se traduz pela recusa do diálogo com as classes populares em torno da comunicação entre o saber científico e o saber popular.

A aplicação do Know-how técnico torna dispensável, e até absurda, qualquer discussão sobre um know-how ético. A naturalização técnica das relações obscurece e reforça os desequilíbrios de poder que as constituem. A aplicação é unívoca e o seu pensamento é unidimensional. Os saberes locais ou são recusados ou são funcionalizados e, em qualquer caso, tendo sempre em vista a diminuição das resistências ao desenrolar da aplicação. (SANTOS, 2009, p. 21). 
Percebe-se que, dessa forma, nesse modelo da aplicação técnica da ciência, há o predomínio de uma cosmovisão única sobre a descrição e a interpretação dos conflitos existentes nas relações humanas no interior da sociedade, os quais são compreendidos e resolvidos mediante a utilização de métodos baseados em uma suposta "neutralidade ética e política", ou seja, não se leva em consideração a ética e a política na perspectiva da realidade social.

Conforme Santos (2001), com a destituição da ética e da política na compreensão, na interpretação e na solução dos problemas inerentes aos seres humanos, a sociedade fica submetida ao modelo hegemônico de ciência que atende aos interesses da lógica da globalização neoliberal que, por intermédio do poder da informação, veicula ideias estruturadas em falsas premissas que pregam a homogeneização cultural do planeta, o desaparecimento do Estado e a difusão de notícias como fator de democratização dessa sociedade.

Essas falsas premissas são sustentadas por uma forte ideologia que domina quase todos os espaços da sociedade, acreditando se viver num mundo de grande progresso técnico e científico posto a serviço de toda a humanidade. Verifica-se, assim, que essa ideologia difunde uma história fantasiosa sobre o mundo atual.

Quando tudo permite imaginar que se tornou possível a criação de um mundo veraz, o que é imposto aos espíritos é um mundo de fabulações, que se aproveita do alargamento de todos os contextos para consagrar um discurso único. Seus fundamentos são a informação e o seu império, que encontram alicerce na produção de imagens e do imaginário, e se põem ao serviço do império do dinheiro, fundado este na economização e na monetarização da vida social e da vida pessoal. (SANTOS, 2001, p. 17-18).

Dessa maneira, a vida fica reduzida ao aspecto econômico. Barcellona (1999) afirma que, hoje, produz-se uma drástica redução do ser social ao ser econômico. Como consequência, as relações entre as pessoas no interior da sociedade acontecem segundo o princípio monológico, em que um dos polos da relação torna o outro objeto com vistas à obtenção de seus propósitos relacionados ao poder e às vantagens econômicas, as quais são obtidas por meio de comportamentos centrados na competitividade e no culto ao individualismo. 
Ao adotar a competitividade como regra, esses comportamentos acarretam um encobrimento do sentido eminentemente humano na convivência entre as pessoas em suas relações sociais, pois a competitividade promove a reificação de um dos sujeitos do relacionamento humano, dificultando a sua participação como um ser atuante na (re)construção e na transformação da sociedade. Nesse sentido, não há comunicação recíproca nas relações entre as pessoas. Há apenas, nesse caso, a emissão de comunicados, por parte de um dos sujeitos, como se somente esses fossem verdadeiros. Essa emissão de comunicados instaura uma educação de caráter opressor, pelo não respeito à alteridade do/a outro/a, já que o princípio fundante indispensável à realização de uma humanidade plena é negado: o princípio dialógico.

Barcellona (1999, p. 184) escreve que as culturas fundadas "[...] sobre o estabelecimento dos princípios [...] da solidariedade e da reciprocidade, parecem ser herança de um passado irrevogavelmente superado." Segundo o autor, vive-se uma época de "desmanche" de tradições, de valores, na qual produzir e distribuir bens ganha novos sentidos. $\bigcirc$ sentido capitalista de viver, tendo como denominador comum o valor de troca, parece preencher o "vazio desse desmanche" pelo individualismo, pela concorrência, pela unidi94 mensionalidade da vida atrelada ao econômico, predominantemente.

No mundo globalizado, esse movimento básico dialógico é praticamente excluído das relações sociais, nos espaços das diversas organizações da sociedade. No seu lugar, emerge a força da competitividade e como consequência traz o aprofundamento do individualismo, do egoísmo, da violência e da guerra entre pessoas, empresas, cidades, estados e nações. Desse modo, a "ética da competitividade" mata a solidariedade e a cooperação.

Os individualismos arrebatadores e possessivos: individualismos na vida econômica la maneira como as empresas batalham umas com as outras); individualismos na ordem da política (a maneira como os partidos frequentemente abandonam a idéia de política para se tornarem simplesmente eleitoreiros); individualismos na ordem do território las cidades brigando uma com as outras, as regiões reclamando soluções particularistas). Também na ordem social e individual são individualismos arrebatadores e possessivos, que acabam por constituir o outro como coisa. (SANTOS, 2001 , p. 47). 
Essas presenças desses individualismos - forjados pela ética da competitividade da globalização neoliberal - geram um quadro de desagregação social, promovendo o agravamento da violência em quase todos os espaços sociais da contemporaneidade. Na acepção de Santos (2001), vive-se sob o signo de uma globalização neoliberal, promotora da reificação das pessoas.

Para evidenciar essa reificação, que se propaga no mundo atual, procurou-se se embasar, a seguir, em citações de Freire (1 996) e Andreola (2011) a respeito da violência e da barbárie imposta aos seres humanos, especialmente com os mais pobres. Em tom de denúncia, Freire (1 996) discorre sobre a radicalidade ética que educandos/as e educadores/as devem assumir nas suas práticas pedagógicas diante do quadro atual, dominado pela ética de mercado excludente, que atravessa a humanidade.

Educadores e educandos não podemos, na verdade, escapar à rigorosidade ética. Mas, é preciso deixar claro que a ética de que falo não é a ética menor, restrita, do mercado, que se curva obediente aos interesses do lucro. Em nível internacional começa a aparecer uma tendência em acertar os reflexos cruciais da "nova ordem mundial", como naturais e inevitáveis. Num encontro internacional de ONGs, um dos expositores afirmou estar ouvindo com certa freqüência em países do Primeiro Mundo a idéia de que crianças do Terceiro Mundo, acometidas por doenças como diarréia aguda, não deveriam ser salvas, pois tal recurso só prolongaria uma vida já destinada à miséria e ao sofrimento. Não falo, obviamente, desta ética. Falo, pelo contrário, da ética universal do ser humano. Da ética que condena o cinismo do discurso citado acima, que condena a exploração da força de trabalho do ser humano, que condena acusar por ouvir dizer, afirmar que alguém falou $A$ sabendo que foi dito $B$, falsear a verdade, iludir o incauto, golpear o fraco e indefeso, soterrar o sonho e a utopia [...]. (FREIRE, 1996, p. 7).

No mesmo tom de denúncia apontado por Freire (1996), Andreola fala da barbárie dos dias atuais a que homens e mulheres estão submetidos, por meio do relato:

Não precisamos de estatísticas para explicar a barbárie. Basta a foto vencedora do Prêmio Pulitzer, tirada por Carter, em 1994, durante a fome que assolou o Sudão. Uma criança agonizante rasteja na direção do campo de alimentos da ONU. Atrás dela, 
um abutre aguarda que ela morra para devorá-la. Diante de cenas como aquela, todos nós sentimos desumanizados. $\bigcirc$ fotógrafo não resistiu. Suicidou-se três meses depois. (ANDREOLA, 2011 , p. 317$)$.

Diante desses relatos eloquentes, proferidos por esses dois educadores humanistas, fica evidente que o nosso compromisso, como educandos/as e educadores/as, diante desse quadro desolador imposto pela globalização neoliberal, deve ser a favor de uma utopia assentada em uma prática político-pedagógica da libertação, inserida na realidade sócio-histórica, com vistas à construção de uma civilização fundada em novos valores, tais como: a solidariedade, o amor, a esperança, o respeito à alteridade, a responsabilidade, a compaixão, a reciprocidade e a cooperação.

Nesse contexto, torna-se fundamental o princípio dialógico, principalmente para a formação de um novo mundo ancorado em pressupostos epistemológicos e em valores políticos da cooperação, da solidariedade, do amor e da compaixão, os quais são os sustentáculos para uma vida voltada para o/a outro/a no sentido de uma comunhão de corpo e alma entre as pessoas nas relações sociais.

movimento básico dialógico consiste no voltar-se-para-o-outro. Aparentemente trata-se de algo que acontece toda hora, algo banal; quando olhamos para alguém, quando lhe dirigimos a palavra, é com um movimento natural do corpo que a ele nos voltamos: porém na medida do necessário, quando a ele dirigimos a nossa atenção, fazemo-lo também com a alma. (BUBER, 1982, p. 56).

Nessa perspectiva, a educação, sobretudo a educação popular, pode ser um dos caminhos, que, por meio da denúncia da barbárie imposta pela lógica do mercado, anuncie um mundo centrado na ética do humano e na esperança como princípios fundamentais para a construção desse mundo, no qual todas as pessoas façam parte. Emerge, portanto, a possibilidade de que todas as pessoas possam ter direito à participação na comunidade em torno da (re)construção e da transformação da realidade social atual com os/ as outros/as, a partir do respeito à diversidade cultural, da compaixão, da reciprocidade, da esperança, do respeito à alteridade, fundada na solidariedade como uma alternativa possível à assunção de um mundo mais humano. 


\section{O papel da utopia na educação popular e na (re)construção de um mundo mais humano e solidário}

Os relatos de Andreola (201 1) e Freire (1996), citados neste artigo, convidam a pensar e a refletir sobre as agruras a que está submetida a humanidade na conjuntura atual, promovidas pela lógica de mercado da globalização neoliberal que, por meio de seus ditames, excluíram e excluem grande parte da população das possibilidades de acesso à cultura, à educação, à saúde, à liberdade e à renda, indispensáveis para uma vida digna.

Esses ditames da globalização neoliberal são apoiados nos fatores da homogeneização cultural, da competitividade, do individualismo e da monetarização da vida, os quais negam o direito à realização de uma civilização cooperativa ancorada no respeito às diferenças, na compaixão, no amor, no respeito à alteridade, na reciprocidade, na esperança e na responsabilidade com o/a outro/a e com a natureza.

Dessa maneira, como contraponto ao modelo de globalização, tenciona-se que seja possível a emergência de uma globalização cooperativa, a partir de uma perspectiva utópica que passa pela educação, especialmente pela educação popular. Esta, por sua vez, tem, entre as suas características, o caráter centrado no diálogo em torno da ética embasada na solidariedade e na esperança, na construção de um mundo justo e igualitário para todos os seres humanos. A educação popular, portanto, pode ser um dos caminhos que proporcione a mudança social, principalmente a partir da substituição da racionalidade técnico-instrumental por uma racionalidade centrada no diálogo entre as diferentes culturas (interculturalismo), que gira em torno da solidariedade entre todas as pessoas, visando ao surgimento de outro projeto possível de mundo.

Posto pois o problema da crise de uma civilização pretensamente superior, que é sobretudo crise da racionalidade ocidental, é óbvia a urgência de se buscar um novo paradigma de racionalidade, e um projeto alternativo de civilização, mais humana e solidária que, segundo Garaudy, deverá guiar-se por uma 'concepção sinfônica'. (ANDREOLA, 2002, p. 135).

Pensar em utopia da educação popular, sobretudo, implica retomar e reafirmar o debate da importância de nossa compreensão e reflexão da 
realidade em interação dialética com nossa ação imersa no cotidiano, com vistas à construção de outro mundo possível. Nesse sentido, é imprescindível conceituar a utopia para esclarecer a que lugar e perspectiva se está fazendo alusão. Sendo assim, trabalha-se com a definição dada pelo filósofo alemão Ernst Bloch, que, de acordo com Freitas (2008, p. 4 18) "[...] relaciona o conceito de utopia com a noção de esperança crítica, apresentando o conceito de utopia concreta em oposição ao conceito de utopia abstrata." Nessa mesma perspectiva, Freire (1992, p. 27) afirma que "[...] o utópico não é o irrealizável; a utopia não é idealismo, é a dialetização dos atos de denunciar e anunciar, o ato de denunciar a estrutura desumanizante e de anunciar a estrutura humanizante."

Concomitantemente, pode-se fazer referência também ao conceito de esperança utilizado por Freire, segundo o qual a utopia passa a ser movida e respaldada por um sonho possível ou então, um inédito-viável. "Paulo Freire aprofunda a compreensão da esperança crítica, considerando que a esperança não é pura espera, nem projeção idealizada; é tanto uma necessidade ontológica quanto uma atitude a ser criticamente desenvolvida." (FREITAS, 2008 , p. 418 ). Vale ressaltar que a esperança não é vista como sinônimo 98 de transformação, tendo em vista que "[...] enquanto necessidade ontológica a esperança precisa da prática para tornar-se concretude histórica." (FREIRE, 1992, p. 111 .

É no estabelecimento das relações dialógicas entre os sujeitos no mundo, a partir do processo dialético de ação e de reflexão sobre as práticas pedagógicas realizadas por esses sujeitos, que se interfere na realidade social para modificá-la. A educação popular, nesse contexto, faz uma mediação entre os sujeitos e o mundo no sentido do anúncio, a partir da denúncia de uma situação desumanizante de opressão e de possibilidades que apontem para um mundo mais fraterno e humano. Isso implica, necessariamente, o reconhecimento da alteridade do/a outro/a, considerando que, nessa perspectiva crítica, somos seres coletivos e não individuais. Dessa forma, pode-se dizer que "[...] a categoria da Alteridade fornece a chave para compreender-se a realidade histórica e aponta a possibilidade de ruptura nas situações de dominação." (GROLLl, 2004, p. 22). Nesse viés, também, concorda-se com o seguinte pensamento: 
Desde a alteridade é possível pensar nosso modo de ser e agir num horizonte de crescimento do outro e da vida, servindo como referência crítica contra os modelos desumanizadores e como horizonte para elaborar novos modos, simbólicos, de autocompreender-nos e produzirmos novas práticas humanizadoras. (SIDEKUM, 2013, p. 158-159).

Reconhecer as diferenças, sem necessariamente transformá-las em desigualdades, constitui-se em um passo fundamental para a mudança do paradigma da globalização neoliberal para uma possibilidade cooperativa nas relações humanas. Torna-se, portanto, conforme Levinas, citado por Grolli (2004, p. 53) "[...] uma reflexão voltada para o âmago da questão ética, enfocando o homem marginalizado, não a partir do Eu vencedor, mas a partir do outro que permanece Outro, porém, não isoladamente, mas em relação com o eu."

Assim, para a mudança do mundo atual da globalização neoliberal para um mundo vindouro de uma civilização cooperativa, é imprescindível que as práticas pedagógicas, a partir da denúncia desse mundo atual e do anúncio de um outro mundo, sejam estabelecidas e realizadas com base na perspectiva da inclusão de todos os seres humanos nos processos sócio-históricos da sociedade, a partir da perspectiva ética. Isso quer dizer que as relações sociais devem ser erigidas com base no princípio dialógico, fundamentado no processo crítico de ação-reflexão sobre a realidade vigente, bem como da comunicação, a partir desse processo crítico de tomada de consciência, de possibilidades condutoras de práticas político-pedagógicas que tenham a ética como alicerce da vida. Desse modo, a vida pode vir a ser construída e vivida com base em princípios éticos sustentados pela presença da humanização em todas as ações das pessoas, humanização esta, que prescinde da ética para se concretizar no cotidiano de homens e mulheres.

Dessa forma, admite-se o mesmo pensamento de Levinas (2007) quando afirma que a vida tem de ser construída com base na ética como Filosofia primeira. Nessa perspectiva, as relações sociais entre as pessoas serão estabelecidas e realizadas com base na reciprocidade da escuta e da resposta da comunicação das palavras proferidas entre os/as participantes da relação, num clima de encontro, envolto pelo diálogo genuíno, em que cada um dos polos da relação acolha o outro, no face a face, como sujeito de partitha e de cooperação, na esteira da esfera do inter-humano, o qual é marcado 
pela reciprocidade ética. Em direção convergente, a que foi enunciada, a respeito da presença do inter-humano, vale destacar que:

De todas as esferas nas quais se realizam tais relações, a esfera do interhumano é a mais genuína. Esta relação entre humanos se manifestou como uma convergência que implica presença e participação mútuas. A ação que se desenvolve é recíproca. A participação conjunta resguarda a alteridade e a individualidade dos participantes na relação. (ZUBEN, 2003, p. 172).

Desse modo, quando emerge o inter-humano, a ação recíproca desenvolvida entre homens e mulheres nas relações sociais, possibilita o aparecimento de práticas políticas e pedagógicas capazes de, na ação-reflexão, realizadas por esses/essas, promover a transformação social com base em uma ética comunitária, que possibilite, a partir do princípio dialógico, a emergência de comunidades de cooperação no mundo, em oposição ao individualismo excludente da globalização neoliberal, que aniquila com a humanização.

Essas comunidades de cooperação, entretanto, acontecem na intercomunicação entre os sujeitos das relações sociais, que, de acordo com Buber 100 (1982), se dá pela enunciação da palavra princípio eu-tu, fundadora do movimento dialógico promotor da reciprocidade entre eles.

eu dialógico, pelo contrário, sabe que é exatamente o tu que o constitui. Sabe também que, constituído por um tu - um não-eu -, esse tu que o constitui se constitui, por sua vez, como eu, ao ter no seu eu um tu. Desta forma, o eu e o tu passam a ser, na dialética destas relações constitutivas, dois tu que se fazem dois eu. (FREIRE, 2005, p. 1921.

Dessa forma, por intermédio da reciprocidade entre os integrantes das relações sociais, se estabelece no interior das comunidades de cooperação a partilha em favor do princípio "nós". Nesse contexto, emerge como protagonista a educação popular, apresentando-se como uma possibilidade de educação que aponte para uma utopia centrada na ética da inclusão de todos os seres humanos e na esperança de um mundo em que prevaleça uma economia voltada para a comunhão e para a solidariedade entre todos os seres humanos, bem como uma política centrada no diálogo, em torno da busca da igualdade associada ao acolhimento das diferenças culturais. 
Quanto mais diferentes são os que convivem num espaço limitado, mais ideias do mundo aí estarão para ser levantadas, cotejadas e, desse modo, tanto mais rico será o debate silencioso ou ruidoso que entre as pessoas se estabelece. (SANTOS, 2001, p. 131).

A constituição desse mundo centrado na cooperação, portanto, implica a presença e atuação dos seres humanos imersos na e com a realidade histórica em torno do diálogo intercultural, cujo fundamento primeiro seja a ética balizadora da busca da utopia da igualdade com o respeito às diferenças de classe, sexo, etnia, gênero, língua e religião. Assim, "[...] a perspectiva intercultural está orientada à construção de uma sociedade democrática, plural, humana, que articule políticas de igualdade com políticas de identidade." (CANDAU, 2008, p. 8).

Essa utopia constitui-se em uma busca por um mundo mais justo e igualitário nas relações humanas, o qual se aprofundará com a ética, ou seja, " [...] com aquilo que a totalidade não pode simplesmente instrumentalizar." (GROLLI, 2004, p. 122). De igual forma, vale salientar que:

Saber escutar a palavra do outro é ter consciência ética, não poder interpretar adequadamente determinada palavra, porque rompe seu fundamento, é aceitá-la simplesmente por respeito a sua pessoa. Arriscar a vida a fim de cumprir com os requerimentos de determinados protestos é lançar-se na práxis do oprimido, é parte do processo do momento. (DUSSEL, 1985, p. 181, tradução nossa).

Assim, a ética deve ser o ponto de partida para impulsionar a esperança em torno da construção desse outro mundo possivel, ancorado na reciprocidade, devendo ser centrado no diálogo entre as pessoas em torno do respeito e da aceitação das diferenças culturais em termos de experiências, saberes e conhecimentos. "A ética da transformação, que segue o imperativo de subverter as relações em que o homem seja menos do que pode ser, será também uma ética da solidariedade." (ALBORNOZ, 1998, p. 14). Dessa forma, todas as pessoas, preservando suas diferenças têm vez e voz na vida das comunidades onde estão inseridas, no sentido da elaboração de projetos que contemplem a todos/as numa perspectiva de uma convivência solidária com vistas à assunção de uma sociedade igualitária. 
Dessa feita, o exercício de uma educação popular como prática de cooperação e de libertação pode contribuir, em conjunto com outros campos do conhecimento, para a emergência de múltiplos processos alternativos interculturais fundados na ecologia de saberes das diversas culturas existentes, geradores de práticas pedagógicas destinadas ao ensino e à aprendizagem de caminhos, seja no interior dos movimentos sociais ou nas demais organizações sociais da sociedade, que engendrem ações impregnadas de cuidado com o ser humano e com a natureza com vistas à transformação da realidade social atual.

Essas ações devem ser edificadas a partir da conjugação das realidades locais, regionais, nacionais e globais em torno de ideias advindas do conhecimento dos paradigmas emergentes do campo da ciência e do campo da educação, associados aos conhecimentos dos saberes populares, construídos com base na experiência das práticas sócio-históricas dos grupos sociais. Assim, caminha-se no sentido da apropriação das aprendizagens (o ofício de aprender) como resultado do aprofundamento da intercomunicação entre as pessoas, num horizonte dirigido para a criação de uma sociedade embasada em valores: da compaixão, da responsabilidade, do amor, do sonho e da 102 esperança com vistas à consecução de uma existência como repartição solidária dos bens simbólicos e dos materiais necessários à manutenção da vida.

Nessa perspectiva da educação popular como prática de cooperação, portanto, o ofício de aprender é visto como um processo político-pedagógico ancorado no princípio dialógico de intercâmbio de saberes e de gestos simbólicos, de modo que:

Pode, e deveria ser imaginado como o exercício humano do alargamento do diálogo. Ou seja, como um dos mais confiáveis caminhos do próprio sentido do que imaginamos ser a vocação humana: aprender a saber e reciprocar o sabido. Um alçarmo-nos juntos partilhando planos cada vez mais densos, mais complexos, mais conectivos, mais recíprocos e, portanto, mais dialógicos de intertroca de saberes e sentidos. (BRANDÃO, 2012, p. 53).

Nessa proposição, a vida é vivida na reciprocidade, de forma que as pessoas cooperam entre si, na busca do "Ser Mais" junto com os/as outros/ as, em substituição ao "Ter Mais" do indivíduo centrado em si, que leva ao egoísmo. Nessa direção, Freire, citado por Andreola (2008, p. 79), esclarece 
que "ninguém pode ser autenticamente, proibindo que os outros sejam. Esta é uma exigência radical. $\bigcirc$ ser mais que se busque no individualismo conduz ao ter mais egoísta, forma de ser menos de desumanização."

Assim, a busca da humanização, em oposição à desumanização, acontece a partir da educação popular, em torno da construção e do fortalecimento de iniciativas que assegurem o desenvolvimento humano voltado para a prática da dádiva entre as pessoas, fundadora de uma economia da cooperação (economia popular e solidária), para a vivência de uma simplicidade voluntária assentada no princípio da suficiência e para iniciativas ambientais, que integrem a ecologia ambiental com a ecologia social.

Nesse caminho, o sonho e a esperança na possibilidade da emergência de um e outro mundo engendram-se nos diversos campos de atuação de homens e mulheres pela cooperação, seguindo a acepção de Mauss (2008) - a vida é baseada em relações ancoradas na dádiva -, o qual se pode originar também das práticas e da teoria da educação popular, ancoradas na reciprocidade, no sentido da perspectiva da construção dos inéditos viáveis, girando em torno da proposição de que a tríade dar-receber-retribuir faça parte naturalmente da vida, como algo proveniente da comunhão entre todos os seres humanos de modo que a liberdade supere a obrigação. Assim sendo, essa tríade

[...] passaria a vigorar entre nós em outros termos. Não mais uma reciprocidade institucional e imposta, mas uma nova maneira de interagirmos fundada integralmente em princípios de partilha, solidariedade e participação. Uma vida onde a reciprocidade deixasse passo a passo a esfera das atitudes interativas obrigatórias, ou cooptadas pela mídia e a empresa, e viesse a ser remodelada por inteiro, de modo a fazer parte das escolhas recíprocas de uma vida social pensada em termos inteiramente outros e para os outros. (BRANDÃO, 2012, p. 65).

A educação popular, por conseguinte, por meio de seu método dialógico e problematizador acerca da realidade social - ver, julgar e agir - pode ajudar na concretização desse sonho de uma nova civilização, em que a vida seja pensada e vivida com base em práticas político-pedagógicas, edificadas a partir de uma racionalidade (re)construída com base na convergência de 
paradigmas, em favor da ética da humanização. Nesse sentido, há a necessidade de:

Reconstruir um grande paradigma humanista e inclusivo, que se alimente dos enfoques do ocidente e do oriente, do norte e do sul. Um paradigma para uma globalização humanizante [...] Um paradigma que na realidade são muitos paradigmas, unificados em torno de princípios éticos de justiça e legalidade. (TORRES, 2007, p. 911.

Vale ressaltar, também, a importância desses paradigmas no processo do fazer pedagógico dos/as atores/atrizes envolvidos/as nos processos de educação popular, principalmente, no que se refere ao ensino e à aprendizagem de conhecimentos centrados em uma nova civilização que está por emergir, em torno do desejo da ampliação de cenários possíveis de transformação social da realidade vigente.

Sendo assim, é imprescindível que a utopia esteja presente nos discursos e nas práticas dos/as atores/atrizes envolvidos/as em processos de educação popular, seja nas escolas ou em demais organizações sociais, 104 opondo-se ao modelo atual da globalização atual centrado no individualismo e na exclusão de grande parte da humanidade. Dessa forma, de acordo com a visão de Cattani (2003), é, a partir do respeito ao outro/a que se poderá almejar a transformação social e a liberdade. Liberdade essa que será alcançada a partir de uma educação popular, que associe a ética como condição primeira para impulsionar a utopia visando ao surgimento de uma vida em que todos/as façam parte, a qual só é possível por intermédio do sonho e da esperança, ou seja, não há utopia necessária à transformação sem sonho e esperança.

Sem um mínimo de esperança não podemos sequer começar o embate, mas, sem o embate, a esperança, como necessidade ontológica, se desarvora, se desendereça e se torna desesperança que, às vezes, se alonga em trágico desespero. Daí a precisão de uma certa educação da esperança. É que ela tem uma tal importância em nossa existência, individual e social, que não devemos experimentá-la de forma errada, deixando que ela resvale para a desesperança e o desespero. (FREIRE, 1992, p. 11). 
A educação popular, portanto, fundamentada na denúncia da realidade da globalização neoliberal, pode apontar caminhos para uma nova globalização, com base em práticas centradas na dádiva e na cooperação entre as pessoas. Dessa forma, apoiados no diálogo dos diversos saberes e culturas e amparados na ética da reciprocidade e da esperança como categorias indispensáveis para a produção de conhecimentos em favor de uma vida mais humana é necessário elaborar, conforme adverte Santos (2007, p. 127) "[...] um conhecimento prudente para uma vida decente $[\ldots]$ ", ou seja, que todos os conhecimentos científicos e populares sejam produzidos com responsabilidade com a vida de todos os seres existentes no planeta Terra.

Assim, a educação popular pode se tornar uma teoria capaz de elaborar uma pedagogia a serviço da lógica da vida plena de todos os seres humanos, sobretudo, no campo da economia.

Movimentos sociais, associações, cooperativas ou outras práticas sociais, podem constituir-se em lugares sociais privilegiados para a reconstrução do coletivo, dos laços sociais rompidos, de reconhecimento e identificação social dos indivíduos. (FRANTZ, 2001, p. 14).

Nessa perspectiva da reconstrução de laços sociais, no contexto atual, o papel da educação popular, a partir das denúncias das situações limites vividas por todos os seres humanos, é de anunciar a possibilidade de inéditos viáveis, forjados no diálogo intercultural, em que se assegurem os mesmos direitos às diferentes culturas, respeitando-as em suas diferenças de classe, etnia, sexo, gênero, língua e religião, com vistas à consecução de um mundo onde se instaurem nas pessoas e na sociedade relações ancoradas na cooperação e na solidariedade nos aspectos políticos, sociais e econômicos.

\section{Referências}

ALBORNOZ, Suzana. O enigma da esperança. Petrópolis, RJ: Vozes, 1998.

ANDREOLA, Balduino Antonio. Dos preconceitos de Hegel ao diálogo das civilizações. In:

Educação, cultura e resistência: uma abordagem terceiromundista. Santa Maria: Palotti/ ITEPA/EST, 2002.

Balduino Antonio. Por uma pedagogia das grandes urgências planetárias. Revista Educação, Santa Maria, v. 36, n. 2, maio/ago. 2011. 
Balduino Antonio. Radicalidade ética da pedagogia do oprimido. Revista de Educação, Ciência e Cultura, Canoas, v. 13, n. 1, jan/jun. 2008. Disponível em: <http:// www.revistas. unilasalle.edu.br/documentos/Educacao/V13_1_2008/05_Balduino_ Andreola.pdf >. Acesso em: 15 jul. 2013.

BARCELLONA, Pietro. Triunfo do ocidente e decomposição da práxis vital. In: OLIVEIRA, Flávia Arlanch Martins (Org.). Globalização, regionalização e nacionalismo. São Paulo: Unesp, 1999.

BAUMAN, Zygmunt. A ética é possível num mundo de consumidores? Rio de Janeiro: Zahar, 2011.

BRANDÃO, Carlos Rodrigues. $\bigcirc$ outro ao meu lado. Algumas idéias de tempos remotos e atuais para pensar a partilha do saber e a educação de hoje. In: MOLL, Jaqueline. Caminhos da educação integral no Brasil a outros tempos e espaços educativos. Porto Alegre: Penso, 2012.

BUBER, Martin. Do diálogo ao dialógico. São Paulo: Perspectiva, 1982.

CANDAU, Vera Maria. Direitos humanos, educação e interculturalidade: as tensões entre igualdade e diferença. Revista Brasileira de Educação, Rio de Janeiro, v. 13, n. 37, jan./ 106 abr. 2008. Disponível em: <http://www.scielo.br/pdf/rbedu/v13n37/05.pdf>. Acesso em: 15 out. 2013.

CATTANI, Antonio David. A outra economia. Porto Alegre: Veraz, 2003.

CAMPOS, Gastão Wagner de Sousa. Um método para análise e co-gestão de coletivos. São Paulo: Hucitec, 2000.

DUSSEL, Enrique. Filosofia de la liberación. Buenos Aires: Ediciones la Aurora, 1985.

FRANTZ, Walter. Educação e cooperação: práticas que se relacionam. Revista Sociologias, Porto Alegre, n. 6, p. 242-264, jul./dez. 2001 . Disponível em: <http://www.redalyc.org/ pdf/868/86819569011.pdf>. Acesso em: 15 jul. 2013.

FREIRE, Paulo. Pedagogia da esperança: um reencontro com a pedagogia do oprimido. Rio de Janeiro: Paz e Terra, 1992.

Pedagogia da autonomia: saberes necessários à prática educativa, São Paulo: Paz e Terra, 1996.

Pedagogia do oprimido. Rio de Janeiro, Paz e Terra, 2005. 
FREITAS, Ana Lúcia Souza de. Utopia. In: STRECK, Danilo Romeu; REDIN, Euclides; ZITKOSKI, Jaime José (Org.). Dicionário Paulo Freire. Belo Horizonte: Autêntica Editora, 2008.

GROLLI, Dorilda. Alteridade e feminino. São Leopoldo: Nova Harmonia, 2004.

GUATTARI, Félix, ROLNIK, Suely. Micropolítica. Cartografias do desejo. Petrópolis, RJ: Editora Vozes, 2000.

LEVINAS, Emmanuel. Ética e Infinito. Lisboa: Edições 70, 2007.

LÖWY, Michael. Ideologias e ciência social: elementos para uma análise marxista. 5. ed. São Paulo: Cortez, 1989.

MARCUSE, Herbert. A Ideologia da sociedade industrial. $\bigcirc$ homem unidimensional. Rio de Janeiro: Zahar, 1973.

MAUSS, Marcel. Ensaio sobre a dádiva. Lisboa: Edições 70, 2008.

MEJÍA, Marco Raúl. Educação e pedagogias críticas a partir do sul: cartografias da educação popular. Rio de Janeiro: NOVAMERICA, 2012.

MORIN, André. Pesquisa-ação integral e sistêmica: uma antropopedagogia renovada. Rio de Janeiro: DP\&A, 2004.

SANTOS, Boaventura de Sousa. Renovar a teoria crítica e reinventar a emancipação social. São Paulo: Boitempo, 2007.

Para uma pedagogia do conflito. In: FREITAS, Ana Lúcia Souza. A Pedagogia do conflito revisitada contra o desperdício da experiência. Porto Alegre: Redes, 2009.

SANTOS, Milton. Por uma outra globalização: do pensamento único à consciência universal. Rio de Janeiro: Record, 2001.

SIDEKUM, Antônio. Alteridade e interculturalidade. In: SIDEKUM, Antônio (Org.). Alteridade e multiculturalismo. ljuí: Editora Unijuí, 2003.

SOETHE, José Renato. Dialética e C\&T: subjetividade e pedagogia. Cadernos CEDOPE, São Leopoldo, v. 8, p. 3-35, n. 13, jan/dez. 1996.

2007.

TORRES, Alfonso. La educación popular: trayectoria y actualidad. Bogotá: El Búho,

ZUBEN, Newton Aquiles Von. Martin Buber: cumplicidade e diálogo. Bauru: EDUSC, 2003. 
Prof. José Wnilson Figueiredo Instituto Federal Catarinense

Campus Concórdia | Santa Catarina

Doutorando do Programa de Pós-Graduação em Educação nas Ciências Universidade Regional do Noroeste do Estado do Rio Grande do Sul | Unijuí Grupo de Estudos de Educação Popular Movimentos e Organizações Sociais | GEEP Bolsista Capes E-mail | wnilsonfi@yahoo.com.br

Doutoranda Liria Ângela Andrioli Programa de Pós-Graduação em Educação nas Ciências Universidade Regional do Noroeste do Estado do Rio Grande do Sul | Unijuí Grupo de Estudos de Educação Popular Movimentos e Organizações Sociais

Bolsista Capes

E-mail | liriaandrioli@yahoo.com.br

Prof. Dr. Walter Frantz Universidade Regional do Noroeste do Estado do Rio Grande do Sul | Unijuí Departamento de Ciências Jurídicas e Sociais Programa de Pós-Graduação em Educação nas Ciências Grupo de Estudos de Educação Popular Movimentos e Organizações Sociais | GEEP Email | wfrantz@unijui.edu.br Recebido 31 jul. 2013 Aceito 9 out. 2013 